\title{
A Portaria no 822/01 do Ministério da Saúde e as peculiaridades das hemoglobinopatias em saúde pública no Brasil
}

\author{
Government Directive MS \# 822/01: \\ unique aspects of hemoglobinopathies \\ for public health in Brazil
}

Antonio Sérgio Ramalho 1

Luís Alberto Magna 1

Roberto Benedito de Paiva-e-Silva 2

1 Departamento de Genética Médica, Faculdade

de Ciências Médicas,

Universidade Estadual

de Campinas. C. P. 6111 ,

Campinas, $S P$

13081-970, Brasil.

2 Centro de Estudos e

Pesquisas em Reabilitação

"Prof. Dr. Gabriel Porto",

Faculdade de Ciências

Médicas, Universidade

Estadual de Campinas.

C. P. 6111, Campinas, $S P$

13081-970, Brasil.

\begin{abstract}
By including hemoglobinopathies in the National Neonatal Screening Program (PNTN), Brazilian Ministry of Health Directive \# 822/01 has taken an important step towards recognition of their relevance for public health in the country. However, except at a few specialized centers, the public health care system is unprepared to meet the goals laid out under the directive. As the first step to effectively implement the guidelines, it is thus necessary to disseminate information on hemoglobinopathies among health professionals working in public health, especially those involved in neonatal screening. This article discusses some of the unique characteristics of hemoglobinopathies in comparison to other metabolic disorders included in the National Neonatal Screening Program. The authors also analyze potential sources of misunderstanding that could jeopardize the program's outcome.
\end{abstract}

Key words Hemoglobinopathies; Neonatal Screening; Public Health; Genetics

Resumo Ao incluir as hemoglobinopatias no Programa Nacional de Triagem Neonatal (PNTN), a Portaria no 822/01 do Ministério da Saúde deu um passo importante no reconhecimento da sua relevância em saúde pública no Brasil. No entanto, com exceção de alguns centros especializados, tal Portaria encontrou a maioria dos serviços públicos de saúde ainda despreparados para colocá-la em prática. Em uma fase inicial de implantação, é necessária, portanto, uma ampla divulgação das hemoglobinopatias entre os profissionais ligados à saúde pública, sobretudo entre aqueles que atuam na triagem neonatal. O presente artigo discute algumas das suas peculiaridades em relação aos demais distúrbios metabólicos incluídos no PNTN. Além disso, é proposta uma reflexão sobre alguns eventuais pontos de distorção que podem comprometer o êxito do programa.

Palavras-chave Hemoglobinopatias; Triagem Neonatal; Saúde Pública; Genética 


\section{Introdução}

Ao incluir as hemoglobinopatias no Programa Nacional de Triagem Neonatal (PNTN), a Portaria no 822/01 do Ministério da Saúde (MS) corrigiu antigas distorções, mas também trouxe à tona importantes pontos de reflexão.

Dentre os benefícios dessa Portaria, devese mencionar a restauração de um dos princípios fundamentais da Ética Médica, que é o da igualdade, garantindo acesso igual aos testes de triagem a todos recém-nascidos brasileiros, independentemente da origem geográfica, etnia e classe sócio-econômica. Realmente, tal triagem era até então restrita a pontos isolados do território nacional, muitas vezes por iniciativa das Associações de Pais e Amigos dos Excepcionais (APAEs) ou das universidades e, algumas vezes, por leis estaduais ou municipais.

Outro aspecto importante foi o de adequar a triagem neonatal dos erros inatos do metabolismo às características étnicas das populações brasileiras. De fato, a triagem neonatal, mais conhecida como "teste do pezinho", limitava-se anteriormente à investigação da fenilcetonúria e do hipotireoidismo congênito, que são condições clínicas importantes, mas de incidência muito menor em nosso país que as hemoglobinopatias, conforme será discutido adiante. Outro distúrbio metabólico contemplado pela Portaria foi a fibrose cística, que também possui grande relevância clínica, embora a sua triagem fique restrita às regiões onde a sua freqüência for significativa.

Para que a triagem neonatal das hemoglobinopatias alcance o êxito esperado, é importante, no entanto, que as suas peculiaridades em termos de saúde pública sejam levadas em consideração. O presente trabalho pretende discutir tais peculiaridades e apresentar alguns pontos de reflexão sobre o tema.

\section{As hemoglobinopatias como problema de saúde pública no Brasil}

Apesar da existência de centenas de hemoglobinopatias hereditárias, apenas três delas exigem a implantação de programas de saúde pública no Brasil: a hemoglobina S, a hemoglobina $\mathrm{C}$ e a talassemia beta. Enquanto as duas primeiras, pela sua alta freqüência entre afro-descendentes, apresentam importância nacional, a talassemia beta possui uma importância regional, em virtude da sua alta freqüência entre os descendentes de italianos (Naoum et al., 1987; Ramalho, 1986; Salzano \& Tondo, 1982). Segundo dados da Organização Mundial da
Saúde (OMS), no entanto, essas três hemoglobinopatias são suficientes para causar um alto grau de morbidade e de mortalidade no Brasil (Penchaszadeh, 1993).

Existem hoje no Brasil milhões de heterozigotos dos genes da hemoglobina $\mathrm{S}$ (heterozigotos AS), da hemoglobina C (heterozigotos AC) e da talassemia beta (heterozigotos AT). A prevalência média de heterozigotos AS é de $2 \%$, valor que sobe à cerca de $6-10 \%$ entre afro-descendentes. A prevalência de heterozigotos AC também é significativa entre estes últimos, com valores entre 1-3\%. Já os heterozigotos AT perfazem cerca de 1-6\% dos euro-descendentes do Sul e do Sudeste (Ramalho, 1986). Praticamente todos esses indivíduos desconhecem o fato de serem portadores assintomáticos (AS, AC) ou oligossintomáticos (AT) desses genes anômalos.

Do casamento ao acaso desses três tipos de heterozigotos, podem nascer em nossas populações, com a probabilidade de $25 \%$, portadores de seis tipos de anemias hemolíticas crônicas e incuráveis, embora tratáveis, ou seja, a anemia falciforme (homozigotos SS), a doença da hemoglobina C (homozigotos CC), a talassemia maior (homozigotos TT), a hemoglobinopatia SC (heterozigotos SC), a S/beta talassemia (heterozigotos interativos ST) e a C/talassemia (heterozigotos interativos CT). A anemia falciforme é a doença hereditária monogênica mais freqüente no Brasil, com a incidência de 1-3/1.000 recém-nascidos, cifra essa cerca de 10 a 30 vezes maior que a da fenilcetonúria (Ramalho, 1986).

As anemias hemolíticas mencionadas acima apresentam gravidade clínica variável, uma vez que estão sujeitas a moduladores de gravidade de origem genética e ambiental. Muitas vezes, no entanto, elas são fatais na infância. As síndromes falciformes (SS, SC, ST), caracterizadas pelo fenômeno da falcização das hemácias, são acompanhadas de fenômenos vasooclusivos, com isquemia, dor, infarto e necrose em vários órgãos. Já as síndromes talassêmicas (TT, CT) e a doença da hemoglobina C (CC) têm o seu quadro clínico centrado na hemólise crônica, acompanhada de hepatoesplenomegalia. O diagnóstico e o tratamento precoce dessas hemoglobinopatias aumentam significativamente a sobrevivência e a qualidade de vida dos seus portadores, diminuindo as suas seqüelas e atenuando as suas complicações clínicas. Daí a importância do seu diagnóstico neonatal.

Em 1992, o MS criou o Comitê de Hemoglobinopatias, responsável pelas primeiras medidas de divulgação e de normatização do tratamento dessas doenças em nosso país. Atualmente, um Grupo de Hemoglobinopatias vem 
assessorando a Gerência Geral de Sangue, outros Tecidos e Órgãos (GGSTO) na implementação da Política de Assistência aos Portadores de Hemoglobinopatias. Dessa forma, a Agência Nacional de Vigilância Sanitária (ANVISA) tem tomado várias medidas de ampla divulgação das hemoglobinopatias, com ênfase, até o momento, nas doenças falciformes. Dentre elas, merece destaque o Manual de Diagnóstico e Tratamento das Doenças Falciformes, destinado a médicos e paramédicos, além do guia do professor e o guia do paciente, com ampla distribuição em todo o território nacional (MS, 2002). Dentre as medidas dessa fase, a Portaria foi particularmente importante.

\section{Peculiaridades das hemoglobinopatias em saúde pública}

As hemoglobinopatias possuem algumas peculiaridades quando comparadas aos demais distúrbios metabólicos investigados no PNTN, que merecem ser levadas em consideração nos programas de saúde pública. Dentre elas, são dignas de destaque e reflexão as seguintes:

\section{Freqüência populacional}

As hemoglobinopatias, ao contrário da maioria dos outros erros inatos do metabolismo, são polimorfismos genéticos humanos, ou seja, são alterações genéticas com alta freqüência populacional. Conseqüentemente, todo programa que se proponha a triá-las em escala nacional deve contar com a infra-estrutura necessária não apenas para confirmar o diagnóstico laboratorial dos recém-nascidos triados, como também para fornecer o tratamento completo para um grande número de pacientes e o aconselhamento genético especializado para um grande número de famílias. Infelizmente, essa infra-estrutura ainda não existe de forma homogênea em todo o território nacional e dificilmente será alcançada a curto prazo. Nesse sentido, a informação e o treinamento dos profissionais que já atuam nos postos de saúde e hospitais públicos parecem ser a estratégia mais adequada no momento.

\section{Tratamento paliativo e preventivo}

Embora tratáveis, as hemoglobinopatias ainda são incuráveis. No caso da fenilcetonúria e do hipotireoidismo congênito, por exemplo, o tratamento fornecido a partir das primeiras semanas de vida (dieta especial e suplementação hormonal, respectivamente) possibilita a cura clínica dos afetados, evitando o aparecimento do retardamento mental. Já no caso das hemoglobinopatias, o tratamento precoce comprovadamente aumenta a sobrevivência dos afetados e melhora a sua qualidade de vida, mas não possibilita a sua cura clínica. Tais indivíduos deverão ser seguidos regularmente em um serviço especializado por toda a sua vida, com avaliações clínicas periódicas e internações hospitalares em situações de risco. Sem o acompanhamento clínico especializado, os benefícios obtidos pelo tratamento precoce não serão consolidados. É indispensável planejar, portanto, a multiplicação em todo o território nacional dos serviços médicos aptos a fornecer não apenas o tratamento inicial (penicilinoterapia profilática no caso dos doentes falciformes e hipertransfusão sangüínea com quelação do ferro nos talassêmicos), mas também o seguimento regular especializado dos pacientes, conforme o estabelecido pela Portaria. Nesse sentido, os hospitais públicos e os hospitais universitários deveriam ser incentivados a implantar as suas unidades de hemoglobinopatias.

\section{Sistema de encaminhamento de pacientes}

As hemoglobinopatias são anemias hemolíticas crônicas, dependentes, em grande parte, dos procedimentos especializados de hemoterapia. Por essa razão, muitas vezes a triagem neonatal e o tratamento dos afetados não são feitos nas mesmas instituições. Torna-se necessária, portanto, a esquematização de um sistema ágil de encaminhamento de pacientes, para atenuar os eventuais efeitos nocivos da dicotomia local de diagnóstico/local de tratamento. Temos comprovado em nossa experiência diária que tal dicotomia pode ser motivo de ansiedade para as famílias dos recém-nascidos triados como portadores de hemoglobinopatias, que nem sempre sabem como obter rapidamente o tratamento, que deve ser iniciado já aos três meses de idade (MS, 2002). Como será discutido adiante, o fato de os laboratórios de triagem neonatal geralmente não estarem localizados na mesma cidade onde residem os recém-nascidos, é um agravante desse problema.

\section{Aconselhamento genético}

A natureza incurável das hemoglobinopatias reforça a importância da sua prevenção. O aconselhamento genético, em um contexto educativo, pode contribuir para reduzir a sua incidência (Zago, 2002). De fato, embora o objetivo principal do aconselhamento genético seja o de permitir a indivíduos e famílias a tomada de 
decisões conscientes e equilibradas a respeito da procriação, ele pode ter, secundariamente, efeitos preventivos (Ramalho, 2002).

$\mathrm{O}$ aconselhamento genético apresenta, no entanto, importantes implicações psicológicas, sociais e jurídicas, acarretando um alto grau de responsabilidade às instituições e aos profissionais que o oferecem. Assim sendo, é imprescindível que ele seja fornecido por profissionais habilitados e com experiência, dentro dos mais rigorosos padrões éticos e científicos.

A Portaria regulamenta o seguimento das crianças diagnosticadas como portadoras de hemoglobinopatias em um Ambulatório Multidisciplinar Especializado, sendo que um dos profissionais da equipe, preferencialmente um profissional médico, deverá ter recebido uma capacitação técnica em Aconselhamento Genético específico para Triagem Neonatal, em um serviço reconhecido de Genética Médica. Trata-se, portanto, de uma regulamentação tecnicamente correta e necessária, mas, frente ao pequeno número de serviços de Genética Médica com tais especificações existentes em nosso país, é importante verificar se o aconselhamento genético em muitos serviços, não ficará, na prática, sob a responsabilidade de profissionais sem habilitação. Esse fato poderá comprometer, já a curto prazo, o sucesso do programa. Parece desnecessário enfatizar o caráter educacional e assistencial do aconselhamento genético, que deve representar, para quem o recebe, um fator de enriquecimento do seu processo de tomada de decisões reprodutivas conscientes. A excessiva ênfase no caráter eugênico do aconselhamento genético, eventualmente dada por um profissional insuficientemente treinado em abordagens não diretivas, poderá desvirtuar os seus objetivos, transformando-o em um processo coercitivo, antiético e gerador de sentimentos de culpa (Paiva-e-Silva \& Ramalho, 1997).

Por outro lado, o profissional que fornece o aconselhamento genético deve estar capacitado a esclarecer todas as dúvidas dos seus clientes, tanto aquelas referentes aos riscos de ocorrência ou de recorrência do problema, quanto aquelas que dizem respeito ao diagnóstico, tratamento disponível e a sua eficiência, possíveis complicações clínicas, possibilidade de diagnóstico pré-natal, grau de sofrimento físico, mental e social imposto pela doença, custo do tratamento e locais que o oferecem, etc.

\section{Triagem de heterozigotos}

Os exames laboratoriais utilizados para a triagem de recém-nascidos com a anemia falcifor- me e outras hemoglobinopatias também identificam os heterozigotos AS, AC, etc. Essa triagem simultânea de heterozigotos assintomáticos (e que não desenvolverão anemia hemolítica) é um dos aspectos que merece maior atenção em um programa de saúde pública. Esses indivíduos, diagnosticados em grande quantidade, em decorrência da sua alta freqüência populacional, correm o sério risco de serem rotulados erroneamente como doentes. Realmente, em nossa prática diária temos testemunhado a aflição dos pais de recém-nascidos AS, quando recebem a carta do Serviço de Triagem Neonatal comunicando que a criança é portadora do "traço falciforme" De imediato, eles podem entender que a criança é portadora de deficiência mental ou de outra alteração clínica importante e persistirão em sua intranqüilidade, até que possam receber, em uma consulta médica, esclarecimentos a respeito do significado benigno do traço falciforme. Nesse sentido, um dos problemas a serem superados é o fato, já comentado anteriormente, de o exame laboratorial de triagem geralmente não ser realizado nas próprias cidades onde os recém-nascidos residem.

A confusão entre traço e doença foi um dos problemas sérios surgidos nos programas norte-americanos de prevenção da anemia falciforme iniciados no final da década de 60 , fruto do despreparo dos legisladores, dos orientadores genéticos e, sobretudo, da imprensa (Wilkie, 1994).

Essa confusão entre traço e doença acarretou sérios dissabores aos portadores norteamericanos do traço falciforme. Muitas companhias de seguro, por exemplo, excluíam os heterozigotos AS, com base na teoria, nunca comprovada, de diminuição da sua expectativa de vida. Da mesma forma, muitas empresas não empregavam portadores do traço falciforme, com o falso argumento de que eles são mais vulneráveis a acidentes de trabalho. Até mesmo a Academia de Força Aérea dos Estados Unidos da América não permitia, até 1981, o ingresso de portadores do traço falciforme (Wilkie, 1994).

É muito importante, portanto, que fique bem claro para os pacientes, médicos e para a comunidade em geral, que o traço falciforme não é uma doença, não é uma forma atenuada da anemia falciforme e muito menos uma forma incubada ou subclínica que pode se transformar em doença em determinadas circunstâncias. O mesmo vale para os indivíduos AC e outros heterozigotos assintomáticos. A falcização de hemácias é excepcional nos heterozigotos AS, só ocorrendo em situações de hipóxia e/ou acidose muito intensas (MS, 2002). 
Uma forma simples de contornar esse problema, que já foi testada satisfatoriamente em outras situações (Paiva-e-Silva \& Ramalho, 1997), seria o envio para os pais dos recémnascidos heterozigotos, juntamente com o resultado do exame de triagem neonatal, de um folheto explicativo sobre o caráter benigno do traço falciforme, traço da hemoglobina C, etc. Essa precaução, embora não dispense as explicações mais detalhadas a serem fornecidas em uma futura consulta médica, poderá atenuar, em grande parte, a aflição dos pais das crianças.

A Portaria representou, sem dúvida alguma, um passo importante no reconhecimento da relevância das hemoglobinopatias em saúde pública no Brasil. Com os devidos ajustes e precauções nessa fase de implantação, ela poderá ter, portanto, um impacto positivo na resolução de um problema de saúde muito antigo em nosso país.

\section{Referências}

MS (Ministério da Saúde), 2002. Manual de Diagnóstico e Tratamento das Doenças Falciformes. Brasília: Agência Nacional de Vigilância Sanitária.

NAOUM, P. C.; ALVAREZ FILHO, E.; DOMINGO, C. R. C.; FERRARI; E.; MOREIRA, H. W.; SAMPAIO, Z. A.; MAZIERO, P. A. \& CASTILHO, E. M., 1987. Hemoglobinas anormais no Brasil. Prevalência e distribuição geográfica. Revista Brasileira de Patologia Clínica, 23:68-79.

PAIVA-E-SILVA, R. B. \& RAMALHO, A. S., 1997. Riscos e benefícios da triagem genética. $O$ traço falciforme como modelo de estudo em uma população brasileira. Cadernos de Saúde Pública, 13:285-294.

PENCHASZADEH, V., 1993. Genetics services for hemoglobinopathies in Latin America. In: Joint WHO/TIF Meeting on Prevention and Control of Hemoglobinopathies, Abstracts, pp. 5-7, Nicosia: World Health Organization.

RAMALHO, A. S., 1986. As Hemoglobinopatias Hereditárias. Um Problema de Saúde Pública no Brasil. Ribeirão Preto: Editora da Sociedade Brasileira de Genética.

RAMALHO, A. S., 2002. Aconselhamento genético. In: Manual de Diagnóstico e Tratamento das Doenças Falciformes (Agência Nacional de Vigilância Sanitária, org.), pp. 35-39, Brasília: Ministério da Saúde.

SALZANO, F. M. \& TONDO, C. V., 1982. Hemoglobin types in Brazilian population. Hemoglobin, 6:85-97.

WILKIE, T., 1994. Projeto Genoma Humano. Um Conhecimento Perigoso. Rio de Janeiro: Zahar Editores.

ZAGO, M. A., 2002. Considerações gerais sobre as doenças falciformes. In: Manual de Diagnóstico e Tratamento das Doenças Falciformes (Agência Nacional de Vigilância Sanitária, org.), pp. 9-11, Brasília: Ministério da Saúde.

Recebido em 9 de abril de 2003

Versão final reapresentada em 20 de maio de 2003

Aprovado em 22 de maio de 2003 